are the subject matter of voluntary self-restraint by the chemical industry; 8 of the latter are restricted in the United States; the European Communities member states decided only a couple of weeks ago to put them on the restricted items list as well.

The law is going to be changed in Germany as far as export control and the participation of German experts in the production of chemical weapons abroad is concerned. These changes, currently within a speedy legislative process that U.S. export sanctions would only slow down, will in some respect exceed international standards: (1) export control, that is, prior authorization, will be extended to know-how, technical data, blueprints, and any other information not generally accessible, wherever gained, unless the export is going to an OECD country; and (2) any direct or indirect participation of German nationals in the production of chemical or biological weapons, including aiding and abetting, will become a criminal offense, punishable by up to 15 years of imprisonment. The Trading With Arms Control Act will be amended accordingly. Germany may have been rightly criticized for a certain leniency in the past; these new rules go beyond the international standard.

But let us not fool ourselves: there is no such thing as an absolutely perfect export control, at least not in countries with 15 million export deliveries every year. There is no absolute guarantee that criminals will not find a way around whatever export control. We have learned the lesson that arms may even be traded to the enemy from the inner circles of government without that government knowing about it. The only way to prevent chemical warfare at any time and in any part of the world is an international agreement that takes up the example of the 1972 Convention on the Prohibition of the Development, Production, and Stockpiling of Biological and Toxin Weapons. As long as some states have chemical weapons, others will want them.

\title{
Chemical Weapons: Designing Operable Systems for ENFORCING RESTRAINT
}

\section{by W. Michael Reisman*}

Discussions about designing systems to restrain what is referred to generically as chemical warfare-the use of chemicals, particularly in gas or vaporous form, against an adversary-have been infected by a number of myths. One of them is that chemical warfare weapons are ineffective. If that were really the case, there would be little problem. But the intensive use of the weapon in the relatively short time period since its perfection and the continued interest it inspires in military specialists should belie this particular myth. No weapon is effective in all contexts, against all adversaries, and for all objectives. Recent history unfortunately shows that chemical weapons are effective in certain arenas and, in particular, in those asymmetrical situations in which one party does not have them and/or the risk of the other responding in kind is minimal or tolerable.

A second myth is that chemical weapons are uniquely nasty and barbaric weapons, whether because of their inherent lack of a capacity to discriminate between civilians and soldiers or because of the pain and suffering they cause their victims. Chemical weapons may have been uniquely nasty and barbaric in 1925. It is arguable whether they still are, when compared to carpet-bombing or fire-bombing of cities or even intensive use of artillery. Nuclear weapons, whether tactical or strategic, score notoriously low when tested by the traditional criteria of international lawfulness, even without taking account of their longer-term environmental consequences.

*Wesley M. Hohfield Professor of Jurisprudence, Yale Law School. 
That particular comparison has already been drawn by weaker nations. It should be no cause for surprise that many of them view chemical weapons as a potential equalizer, an affordable and accessible poor man's atomic bomb, to use the hyperbolic expression that has become current. Middle Eastern states were criticized in the Western press for trying to disrupt the recent Paris Conference by linking the dechemicalization of their arsenals with the denuclearization of Israel's, but the connection is not incomprehensible or perfidiously wicked.

A third myth is that, until recently, the prohibition on the use of chemical weapons, explicitly and authoritatively stated in 1925 , had been effective. The Geneva Protocol of 1925, prohibiting the use in war of asphyxiating, poisonous, or other gases and bacteriological warfare methods, may have expressed the policy of its signatories, but whether by design, oversight, and/or circumstances beyond its control, the Protocol has failed to restrain the continued development and use of these weapons. Without an enforcement mechanism, indeed without a mechanism for determining whether current or latent adversaries have the weapon, prudent security specialists apparently believe that they have no choice but to develop it and to plan for its contingent use.

Public attention has been selective and collective memory short. The Protocol has never constituted an effective legal regime. Shortly after the Protocol was concluded, Spain used up its World War I mustard gas arsenals on rebels in Morocco. The action was not sanctioned. Italy used poisonous gas in its conquest of Ethiopia and Japan used it in its conquest of Manchuria. The United States used various gases and defoliants in Vietnam. Egypt used chemical weapons in its Yemen adventure. Iraq used them extensively and, apparently, with considerable effect against Iran. They have been reported to have been used in Cambodia. The Soviet Union has been accused of using them in Afghanistan. Iraq used them with devastating effect against its own Kurdish population, particularly at Halabja. A large number of states are apparently engaged in massive production of these weapons with, as yet, no sanction.

A fourth myth is that chemical weapons are used only as an instrument of last resort. In all of the cases just considered, including Iraqi use of chemicals against Iran in the Gulf war, none of the users was faced with the prospect of political annihilation if it did not use the weapon. Many of the campaigns were overseas adventures which were not of primary political importance to the users. When chemical weapons were used, chey were weapons of choice, selected, in every case, for what was believed to be their comparative economy and effectiveness.

There are many dramatic cases in which chemical weapons were not used. But it was not because of the Protocol or some other codified or customary international legal prohibition. Chemical weapons have not been used in circumstances in which adversaries were symmetrically equipped and had concluded that each would be better off if the weapon were used by neither, allowing a tacit regime to that effect to operate. Those who, in these circumstances, refrained from deploying this weapon frequently explained their restraint as a reflection and expression of their superior humanity, their law-abiding national character, or their perception that the weapons were ineffective. International lawyers who are always eager for examples of the effectiveness of international law, were quick to cite these standoffs as demonstrations of how well the system could operate.

But given the fact that comparably undiscriminating weapons were used in massive amounts by some of these same belligerents in other contexts, the self-invocations of humanism appear to be little more than a part of the deep-seated syndrome of conflict: everyone in a fight tends to believe that he is right and that his cause is better. As for the lack of utility of the weapons, it is significant that some of the belligerents who 
refrained from deploying the weapon in confrontations with a symmetrically equipped adversary, used the weapon without restraint in asymmetrical contests.

Nor is it clear, Geneva Protocol and statements of doctrinalists notwithstanding, that the use of chemical weapons, no matter what the purpose or the context, will automatically lead to a meaningful and politically significant international condemnation. It was no secret that Iraq was deploying the weapon widely and often effectively during the final years of the Gulf war. If there was international protest, it was mild and could only have led Iraq (and similarly situated states) to conclude that it could use the weapon with impunity. Given the tepid and short-lived emotions that the weapon's use in that arena aroused, it is not surprising that in the last months of the war, the Iraqi foreign minister, in a news conference in Bonn, said directly, in response to a question, that his government had used and would continue to use the weapon.

The current outcry against chemical weapons use has come, conveniently, after the Iran-Iraq war, and it has come, largely and loudly, from a group of states that had been very concerned that Iran might win that war. Iraq was dependent, in some cases desperately, on many of these states for funds and military materièl, yet, as long as victory was in the balance, these same states did not even try to exercise the potential control they had over the Baghdad Government to restrain Iraq's chemical weapons use. Their current concern seems to be arresting the spread of the weapons to other Third World countries. But, for reasons I will examine in a moment, the result of the Paris Conference of 1989 was an ambiguous document which did little but restate the already demonstrated ineffectiveness of the 1925 Protocol.

Given the nature of the weapons concerned, their relative effectiveness for some politico-military objectives, and the ease with which they may be produced, even in relatively nonindustrial states, it is clear that no government that views itself as a potential target for this weapon will yield its prerogative of producing the weapon in the absence of a credible and effective international regime. In view of the absence of an enforcement system and the ease of production and concealment of the weapon, such a regime has proved elusive.

For the international lawyer, the urgent item on the agenda is not so much the fashioning of verbal formulas as it is the design of regimes that can retard a juggernaut that threatens to disperse the weapons widely and increase the probability of their use in conventional as well as unconventional international warfare. I use the term regime, not in its current fashionable sense, but simply to mean a social system with an operative normative component that is specialized to this problem and is minimally effective in establishing appropriate norms and putting them into effect.

A number of regimes that might, theoretically, accomplish this objective can be imagined. Each presupposes a different system of verification and enforcement. These aspects, of course, are indispensable to the viability of any regime seeking to restrain development and use of chemical weapons. Since most of the imaginable regimes cannot do this, the inability to meet verification and enforcement requirements will effectively rule out a regime that would otherwise be morally or tactically attractive.

Let us consider six such regimes: (1) a regime based upon nonpossessory norms; (2) a regime based on non-use norms; (3) a regime based on non-first-use norms; (4) a regime based on deterrence by qualitative and quantitative parity in chemical weapons available to adversaries; (5) a regime based on reciprocal deterrences, providing for asymmetrical but functional parities between adversaries; and (6) superpower-supervised nonpossession regimes. Let us sketch briefly the structures, operability, and implications of each of these potential regimes. 


\section{Regimes Based Upon Nonpossessory Norms}

The optimum regime, if it could be achieved, would effectively prohibit the manufacture and storage of all chemical weapons. This regime would have to be universal, for membership in latent war communities may change and "mavericks"-states that choose not to participate in the regime-could suddenly join an adversary's camp, making available to its new friend its chemical weapons arsenal, while reducing the power position of the complying party.

This regime would also require a highly effective and credible verification system. Without it, cheaters would be detected only at the moment of deployment of the weapon, at which time they would, in effect, be rewarded for having violated the regime. But verification of nonproduction is particularly difficult; many battlefield-effective chemical weapons may be produced from mundane industrial chemicals, which would be present in advanced as well as moderately industrialized production systems without causing suspicion. In September 1988, the Wall Street Journal wrote: "Take a 20-year old Russian ballistic missile, readily available on the world market. Install a hollow warhead with tiny vents that blow open as the missile nears its target. Then pour in a compound that any competent lab can mix up from off-the-shelf ingredients: nerve gas." Since effective vehicles for the delivery of such weapons are becoming more common and are likely to be even more so in the future, as inexorable technical advances obsolesce current models, it would be relatively easy for a cheater to adapt missiles designed for conventional warheads for delivery of chemical weapons. Problems such as these have led security specialists in more powerful states to doubt the prospects of this type of regime.

The primary means of effecting a nonpossessory regime are export controls and verification. Each presents problems. Given the ordinary and multiple-use character of many of the chemicals in question and their prevalence in the ordinary stream of commerce, export controls in this area, while not impossible, would be particularly expensive to administer and burdensome on producers and distributors. Since collective export controls are negotiated down to the lowest common denominator, even the prohibited list itself often becomes a predesigned lex imperfecta. The EEC regulation of February 20,1989, is an example of this sort of effort. Its effectiveness remains to be tested.

For Western states, on-site verification is always a two-edged sword. Given the openness of their political systems and their private media, concealment of a clandestine production and storage system, over all but the shortest term, is virtually impossible. For many adversaries, concealment of production or storage, even with an on-site verification system in place, is still possible, given greater control of internal information. On the other hand, verifying the compliance of the West becomes essentially an opportunity to conduct general and industrial espionage.

For some regimes, it is better to get something than nothing. For other regimes, less than a complete system may be worse than no system at all. A nonuniversal nonpossessory regime would be effective, ironically, only for states that knew that there was no chance that they might fight each other. Such states can always afford the luxury of elegantly formulated and high-minded humanitarian law codes. As for states that viewed each other as active or latent adversaries, a nonpossessory regime that was not universal would create an intolerable anxiety if current or latent adversaries were believed to be able to acquire chemical weapons from some other possessor. The absence of universality in this type of regime would generate constant pressure to cheat and thus generate and nurture the seeds of its own breakdown. 


\section{Regimes Based on Non-Use Norms}

A second possible regime would bypass the question of prohibition and stockpiling and base itself upon reciprocal promises not to use an effective weapon that each possesses. In the nature of things, these are the sorts of promises whose vitality and credibility decrease as the costs to the weapon-holder for non-use increase and the gains for its use become more attractive.

Degeneration of commitments along with the pressure to make expedient unilateral calculations of the advantages to be gained by violating them is, of course, a characteristic feature of conflict. Non-use regimes do not ignore this dynamic. On the contrary, possession of the same weapon by the adversary is expected to help to enforce the promise. But non-use regimes are effective only if the parties are in a position of parity and first-use does not preclude counter-use by the other party. That situation may obtain for nuclear weapons when neither party has a first-strike and knockout capacity. It does not obtain for chemical weapons.

One advantage of a non-use regime is that it avoids the formidable problems of verification of nonproduction, nonstorage and nonpossession while focusing on a principal objective of any arms control regime: that the weapon not be used. Given the absence of a centralized enforcer, this sort of regime does hold out the promise of being self-enforcing.

The recent history of the use of this weapon indicates (though it does not prove) that where states are symmetrically equipped, they refrain from using it. There are also substantial costs to this regime. It encourages all current nonpossessors who anticipate any belligerency to acquire the weapon as soon as possible, leading to a rapid proliferation. Insofar as improvements in materials and delivery systems are possible, an arms race in this particular weapon develops. If one assumes that the more widespread these weapons are, the more likely they are to be used (which is not necessarily correct), then this regime would appear to increase the probability of chemical weapons use.

\section{Regimes Based on Non-First-Use Norms}

Assuming that a regime based on nonproduction and nonpossession cannot be established and a regime of non-use can neither be put in place nor be made credible, an alternative and related regime involves interlocking commitments-whether by treaty or serial unilateral declarations-not to use the weapon in question first. In some ways, as we have seen, this regime is the implicit sanction of the one we have just considered.

Where the weapon in question has proliferated, this sort of regime is no small accomplishment. Indeed, at the moment, it appears that chemical weapons are rapidly becoming, in the minds of security specialists in many latent war communities, a weapon whose deployment depends primarily upon tactical and strategic considerations without regard to legal ones. Reference has been made to the statement by Tariq Aziz, the Iraqi foreign minister, defending the use of the weapons as normal. In the light of these developments, the installation of a non-first-use regime would be something of an accomplishment.

One advantage of a non-first-use regime is that it also avoids the formidable difficulties of verification with regard to production and possession. Its only verification problem is whether or not the weapon has been used, which is readily determined and essentially sanctioned by the other party, who then feels legally free to use the weapon. 
If the previous regime encourages proliferation and arms races in this type of weapon, it is obvious that non-first-use regimes do so even more intensely.

\section{Regimes Based on Symmetrical Parities}

If all actors are rational (in the specific sense in which we use the term in our civilization) any symmetrically equipped, and if the use by one actor of a particularly destructive weapon will prediciably call forth a comparably destructive and unacceptable consequence, then reciprocally available weapons that lack a first-strike, knockout punch will deter each actor from using them. The premium shifts to strategies of conflict-avoidance; if conflict occurs, a key objective of strategic planning is avoidance of further escalation. This is, in effect, the metaphysics of the superpower deterrence achieved by mutually assured destruction (MAD). The superpowers have not engaged in maximum war, though that fact is not proof that MAD works: post hoc does not mean propter hoc.

Despite the fact that the superpowers have used MAD as the basis of their reciprocal strategic policy for several decades, they have not extended it to chemical weapons. They resist an unrestrained proliferation of chemical weapons until a de facto symmetrical parity regime might be established between all pertinent explicit or latent war communities. Obviously, nonproliferation regimes, by their nature, serve the interests of those already endowed with the weapon in question, by maintaining the exclusivity of their particular base of power. With chemical weapons, there are a number of other cogent reasons for consciously avoiding parity through a proliferation policy.

First, superpowers cannot assume that elites in some Third World governments are symmetrically rational, i.e., not rational in the sense that they are. Some cultures are actively chiliastic, out to accelerate the inevitable; some cultivate martyrdom. Second, they cannot rely on institutional checks as an additional restraint on what they would characterize as irrationality. While many political systems may tend to elevate psychopaths to high positions, some Third World governments lack the institutional articulation and the checks and balances, the argument goes, to restrain their crazies in a crisis. Under this theory, the same sort of a madman in Washington is going to behave differently from his counterpart in Tripoli, because Washington is a governmental structure in which power is shared among a complex elite all woven into a fabric of multiple controls while Tripoli is, to use Ilich's piercing expression, "a broad based needle."

A third reason is that, unlike nuclear weapons, chemical weapons, given their nature and military applications, are not a real omnibus deterrent. In a bipolar system in which there are rough nuclear parities and neither side enjoys a first-strike, knockout advantage, nuclear weapons are an effective deterrent. This is not the situation for chemical weapons. Two adversaries with equal arsenals of chemical weapons may be so unequal in total war-making capacity that the stronger may decide to use the chemical weapons if it believes it to be to its advantage. Their proliferation does not mean more deterrence (which is debatable even in the case of nuclear weapons), but more opportunity for adventure.

If chemical weapons are effective, their proliferation can change the power balance. For some conflicts, they may even prove to be the poor man's atomic bomb, at least in a deterrent sense. The problem is that because they cannot deliver a knockout, like their strategic nuclear cousins, they will not provide perfect deterrence, but simply shift the rewards for military adventurism into a different configuration. 


\section{Regimes Based on Deterrence by Asymmetrical Parities}

All of the previous regimes single out chemical weapons as a special problem. That treatment may be based on emotional rather than rational considerations. From the perspective of a security specialist in state $A$, it is not the per se possession of chemical weapons by state $B$, a latent adversary, that matters as much as the bottom lines of $A$ and $B$, when the full arsenal and warmaking capacity of each has been totalled up. If B has chemical weapons but $\mathbf{A}$ can still prevail in any of the confrontations it anticipates, public expressions of concern about chemical weapons by A's security specialists are either for purposes of propaganda or the symptom of an irrational cathexis.

Since a major, though not exclusive, objective of all weapons control regimes is to deter their use, seeking strictly symmetrical parities in terms of quantity and quality of weapons may not achieve that objective. Parity in weapon A may become irrelevant if there is a significant disparity in weapons $B$ and $C$. Or parity in weapon $A$ may be tilted in favor of one of the parties if contextual factors make weapon A more effective for one of the parties. If two parties are each equipped with the same quantities and quality of chemical weapons, factors such as the defensive terrain or prevailing wind pattern of one of them may make the use of chemical weapons by the other extremely effective. The situation may not be reciprocal.

These remarks underline the fact that the calculation of parity between belligerents requires much more than the simple inventory of a single weapon, indeed of many weapons. Many other contextual factors must be incorporated into the calculation. In many cases, numerical parities of certain weapons may in fact tilt decisively in favor of one of the parties, because of other contextual factors. Hence, if the objective is deterrence, one might better seek bottom-line symmetries.

The point may be illustrated by one often commented upon example. In the Middle East, the Arab countries outnumber Israel. A number of Arab states are rapidly equipping themselves with chemical weapons. Were a major Middle Eastern war to be fought with these weapons, Israel would presumably be at a serious disadvantage, even if it deployed chemical weapons in return. But Israel is widely believed to have several hundred nuclear weapons, some, it has been speculated, designed for tactical use. Examples such as these demonstrate that an effective bottom-line or an asymmetrical parity may be struck by mixes of weapons. The possession of chemical weapons by one side could be effectively deterred by the possession of nuclear weapons by the other.

While this sort of regime may promise deterrence, when it operates it is expensive, diverting large sums to the expansion and constant updating of weapons. It is also potentially destabilizing. Since weapon development occurs in a jagged fashion, this regime may suffer periods of disequilibrium in which one state, discovering that it has a momentary weapons advantage, may be tempted to seek to realize political gains by threatening momentarily credible military action or actually engaging in it.

This regime, in contrast to many others, ceases to view chemical weapons, as such, as particularly obnoxious to international law and, as a result, may encourage their development and proliferation. That is viewed, in this context, as a matter of lesser importance since what is sought in a regime of deterrence by asymmetrical parities is a cumulative and contextual parity which is often based on asymmetric possession of weapons. 


\section{Superpower Supervised Nonpossession Regimes}

All of the regimes considered until now have been premised on the notion of effective equality among the state actors involved in them. This is a presumption that is fundamental to formal international legal theory. In fact, of course, there are extraordinary disparities between states. Some authoritative international legal regimes, the most prominent being the United Nations Security Council, have incorporated and utilized those disparities in order to make themselves effective.

Some arms control agreements have been built on power disparity. The complex international legal regime of limiting the testing and restricting the proliferation of nuclear weapons is essentially a superpower agreement which each power tries to enforce within its own magnetic power field. These regimes are asymmetric in a unique way. The superpowers reserve their arsenals of the weapons. The weapons serve to further supplement their military superiority, increase their capacity to enforce the regime, and reinforce their hegemonic dominance, to an extent legitimizing it.

The nonsuperpower states that join these regimes, whether voluntarily or by constraint, do not acquire the weapons, a disability that is enforced by the proximate superpower. Thus the regime is symmetrical in a horizontal sense as between the superpowers, each of whom is equipped with the weapon and between those subordinate to the superpowers, each of whom is not equipped with the weapon, but the regime is asymmetrical as between the superpowers and those who are subordinate to them. In this respect, regimes such as these, while exploiting such power disparities, tend also to reinforce them.

Such regimes are totally effective only insofar as the superpowers who have struck an agreement between themselves are able to police all other players. Where, as in the current power process, there are a variety of mavericks, the possibilities of the development and use of the prohibited weapons (whether nuclear or chemical) by these outsiders continue and, in certain types of conflict, could undermine the regime.

\section{International Gendarmes: Toward a Synthetic Regime for Controlling Chemical Weapons}

None of the suggested regimes I have reviewed is ideal for the control of chemical weapons. Some, given the properties of the weapons and the fragmentation of the international political process, promise no success, though they might be effective in other contexts or with regard to other weapons. Nor is it certain that there is a real political will to pay the costs necessary to secure an effective regime. Assuming, however, that there is, a synthesis of different aspects of some of these different regimes might, in the present context, offer the best available method for controlling the proliferation and likely use in the future of chemical weapons.

It is no more practical now to seek a total ban of chemical weapons than a total ban of nuclear weapons. In this respect, the world finds itself as it did with regard to nuclear weapons in 1963. A total prohibition was unachievable and, perhaps, undesirable given the system of reciprocal deterrence between the superpowers that was then the foundation of minimum order. Chemical weapons, when held by major, symmetrical nuclear-equipped adversaries are either neutralized or, ironically, eufunctional, for they help to deter each side from using them. The expectation that each side has such weapons obviates the need for a system of verification, one that would be extremely difficult to achieve given the nature of the productive processes concerned.

Hence a feasible goal in this area is a nonproliferation agreement with a policing system undertaken by a small group of states whose membership possesses the weapon 
but has established a common policy of seeing that others do not. For convenience, I will refer to these states as an international gendarmerie. The actual composition of such a gendarmerie will depend on many factors. It might be the permanent members of the Security Council or any other functional elite.

The superpowers and the other permanent members of the Security Council might agree, in a convention, to act to limit the proliferation of chemical weapons and to discourage their development in those parts of the international political system in which the member has a large measure of effective control. This system could be partially monitored by a reporting system that would operate both internationally and nationally and that would attempt to track the diffusion of materials, in suspicious quantities and/or contexts. OECD economic monitoring, COCOM and EEC procedures and other techniques such as end-user certificates provide models for such a system. At the national level, agencies that monitor foreign trade, might reportusing direct and indirect means of intelligence gathering - the transfer of quantities of chemical materials and productive facilities likely to be used for the production of chemical weapons. That is not as difficult as it seems. Despite the early protestations of the Kohl Government in the Imhausen affair, the Federal Republic's investigative commission now indicates that the diversion was known-from multiple sourcesfrom the early 1980s. Active monitoring would permit the early identification of a new chemical weapons developer-cheater or maverick-and make it possible to direct at it a variety of sanctions that might be mounted unilaterally or in international collaboration.

But it is unrealistic to assume that monitoring mechanisms will always work or that prescribed sanctions will always be able to deter a determined cheater. Mavericks will not be subject to the agreement and, presumably, will develop and stockpile the weapons. If membership in war communities changes, as often happens, the maverick's chemical arsenal may suddenly acquire a decisive military valence in another context. In those circumstances, the weapon will be used. If this probability can be anticipated, the regime will never work. Then Vice President Bush put his finger on this problem in 1984, when he said, "the nations guilty of chemical warfare must pay a price. They must know that violation of the ban against the use of such weapons carries a heavy penalty. Not just a fine or a minor sanction that can be ignored." It is precisely on this point that the Paris Declaration vacillated, expressing concern over recent uses of chemical weapons but only calling for humanitarian assistance to the victims. There was no mention of punishment for the users.

The synthetic regime I am proposing seeks to restrain proliferation but it is less concerned with possession than with use. If mavericks or cheaters should be engaged in a war in which their control of the weapon gives them an advantage, the synthetic system will prove as ineffective as those based on nonpossessory, non-use or non-firstuse norms, unless the authorized possessors-superpowers and others in that small circle-are willing to take an active role. The political costs of establishing and then meaningfully participating in a sanctions program are so high as to make the proposal unrealistic. On the other hand, the effect of sanctions can be secured, if the gendarmerie provides the victim with the weapons necessary for retaliation in kind. Given the fact that there will be enough members in the gendarmerie to assure that at least one will see its interest in the regime as outweighing its interest in short-term gains of one side in the armed conflict prevailing, at least one gendarme will supply the chemical weapons necessary for a counterstrike.

Thus, the ultimate control of the synthetic regime would be a declaration by the gendarmerie, whose members were themselves authorized holders of chemical weap- 
ons, that, jointly or severally, they would supply weapons and delivery systems to a party that had been attacked with chemical weapons if that party did not have such weapons at its own disposal. Thus, possession of the weapons by those who are deterred from using them inter se can serve to restrain their use by others.

\section{Conclusion}

The synthetic regime presupposes a wide measure of agreement among the major powers that, whatever the short-term advantages for one of them caused by the use of chemical weapons in a local conflict, the general use of the weapon is so much against their common interests that they will use force (or allow force to be used) against one of their allies or current or prospective protégés that cheat, or a nonregime maverick. The Gulf war, the Halabja incident, and the resistance to firm action against Libya and now Egypt are hardly encouraging examples of the depth and reliability of the consensus required to make this most feasible of control regimes effective. At least in the near future, the presuppositions necessary to make this regime effective appear to be quite remote from reality.

The prospects for enforcing restraint on chemical weapons development and use are not encouraging. It is more likely that they will be used in local wars in which the parties are asymmetrically equipped, and in internal conflicts, which will be quantitatively the greater part of military violence. The intensity of condemnation will be a function of the political implications of the weapon's use. In any case, sanctions are unlikely. By the time they have developed, if at all, new generations of biochemical weapons at the superpower level will have emerged, largely obsolescing the first and second generation chemical weapons that concern us now.

Ambassador WARNKE responded to the suggestion that it really does not make a difference whether or not these weapons are banned. He said that although it is not the most serious problem we face, it is still worth the attempt. The START talks and a conventional military standdown in Europe are more important and deserve a higher priority than a chemical weapons ban. Nevertheless, he emphasized that for the United States it was a no risk situation-even if we get rid of our chemical weapons and somebody else does not, it does not preclude our effective response. He said that, in fact, he could not foresee a scenario where we would respond to a chemical attack in kind.

Ambassador HANSEN responded that he could not think of a scenario where we would have the weapons to retaliate in kind. He also stated that he did not want anyone to leave thinking that he believed that a discussion of international treaties did not involve questions of international law. What he did say was that the Paris Conference was not a question of international law; it was a political event with a political result-a political statement condemning the use of chemical weapons.

Professor STEIN stated that he shared Professor Reisman's skepticism about the effectiveness of export controls. It would be more effective to have them on an OECD-wide basis, because they would be even less effective if you could buy freely what you needed next door. He said that in the end, it was his opinion as well that export controls are not the key to success in this area.

Professor RUBIN said that he was in the novel position of being in fundamental agreement with nearly everything that had been said so far. He asked Professor Reisman for a definition of a word he had not heard before, the verb "to obsolesce." He stated that with the scope of Professor Reisman's sixth regime, there is a lot of room for play. He said that he saw it not as a hegemonical superpower supervised regime, but rather as controlled by a group of concerned states, including the superpowers. In 
response to Ambassador Hansen, he stated that what he had gathered from the Ambassador's remarks was that the Soviets conceal the true size of their stockpile, they lie as to the quality of their weapons, they lie as to the location of their weapons, and they only destroy their older weapons. He asked how then we were supposed to come to an agreement which presumes that the Soviets will not lie or conceal. He was, therefore, less optimistic about the future course of the negotiations than was the Ambassador. He also replied to Ambassador Warnke that he did not believe this was a great power problem, but rather a global problem. It is the smaller countries that are more likely to stockpile and use these weapons. Hence, he did not believe that a U.S.-U.S.S.R. agreement of verification was that important to solving the overall problem.

Ambassador HANSEN replied that all he was trying to demonstrate was that the Soviet attempts to defuse suspicion have only resulted in more suspicion. His point was that this suspicion must be dealt with if we are to achieve a viable accord.

\section{Discussion}

Peter D. TroobofF:* Dr. Stein has said that the West German Government has announced its intention unilaterally to extend its export control regime further than that of the United States. It should be noted that the U.S. regime would have prohibited the export of the plant because of our Libya controls-not our chemical plant controls. The U.S. has unilaterally controlled, within the last few months, a series of precursor chemicals which our other allies have not controlled. Dr. Stein's point, that the Federal Republic of Germany is now planning to control technology that the U.S. does not control, is most significant.

Dr. Stein also stated that he was concerned about pending U.S. legislation proposing to punish foreign companies that do not behave as we believe they should and that are not adequately punished by their own governments. Dr. Stein, if our own government, together with all of the governments possessing chemical weapons capabilities, were to agree to a regime of controls, do you think it would then be appropriate for each government to adopt measures punishing foreign companies not adhering to this regime?

Professor STEIN: If the Western nations have such a joint regime, I would prefer that any black sheep companies be punished back home.

HARRY ALMOND:** I think we all agree that the control of chemical weapons is dependant upon two things: (1) A verification regime effective in ensuring compliance, and (2) If compliance fails, then we have to move into a sanctioning regime, complete with punishment making it effective, as Professor Reisman has indicated and to which others have alluded. I will set up a short scenario and then pose a question. Israel is under attack by neighboring Arab states relying upon new chemical weapons, which are aimed at airfields and other military facilities, and are persistent for three months. The chemical weapons are used to deny to the Israelis the use of very significant military assets, and the level of human casualties is very low. It is also known to everyone that the Arab states possess CBW weapons which they are holding back on using in order to deter an Israeli nuclear attack. Under the U.S. verification proposal, to what extent are we able to determine in advance the capabilities of a country to very rapidly start up the clandestine production of chemical weapons; just how far does our verification proposal extend?

\footnotetext{
* Of the District of Columbia Bar.

**Professor, National Defense University.
} 